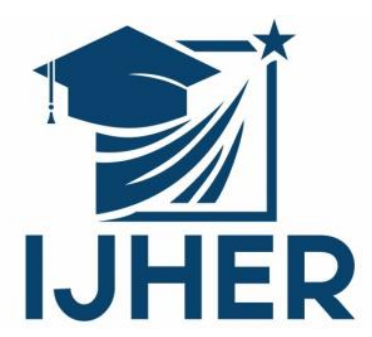

International Journal of Humanities and Educational Research

Volume 2, Issue 2, June 2020, p.23-44

İstanbul / Türkiye

\title{
FUTURE EDUCATION FOR KINDERGARTEN TEACHERS
}

\author{
http://dx.doi.org/10.47832/2757-5403.2-2.2
}

\section{Ban Ismail MAHMOUD ${ }^{1}$}

ISSN: 2757-5403

Article Information

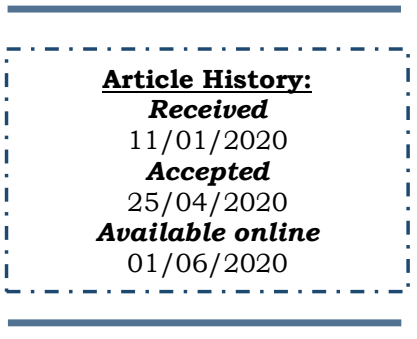

This article has been scanned by iThenticat No plagiarism detected

Copyright $($ C Published by Rimak Journal, www.rimakjournal.com

Rimar Academy, Fatih, Istanbul, 34093 Turkey All rights reserved

\begin{abstract}
Future education or the vision of the future ineducation is that it occupies abasic position in the process of change that have aclear impact on his future, so it is the pracess of future orientalism, and a process inherent to the individual since the beginning of creation, so future eduction and its dimensions for the development and education is considered basic.

Education,whether as variable for societal trans formation or aprimry driver for this trans formation is byvirtue of its role and nature the most vulnerable aspects of Socity to changes that the future entails and the challenges it imposes will necessanily bring about violent changes in the education system its philosophy, its role and its institutions meathods and methods.

The cldrrent researchaims to identify;

1. Dimensions of future eduation for kindergarten teachers To achive the goals;

1.1. The res carcher did the folloing;

1.1.1. The future Education Dimensions scale (Ryoosh) 2019 was adopted, consisting of (46) paragrafs. The researcher vesified the distinct strength.

And internal consistenay the results of the concluded that

1. Kindergarten teachers to not have the scientific and future dimesion as.

The difference was not statistically significant the researcher recom mended som recommedations;

1. The role of the ministry of Education to encourage and streng than kindergarden techers by providing allrequirements and faci that help themin educationg children.

2. Working to pay attention to all future dimensions of female teacher.

The researcher reached some suggestions;

1. Asimilar study on university. Students in all majors and for both sexes, males males - females.
\end{abstract}

\footnotetext{
${ }^{1}$ Dr., Education Directorate, Rusafa-1, Ministry Education Baghdad, Iraq.

\section{IJHER}

International Journal of Humanities and Educational Research

Volume 2, Issue 2, June 2020, p.23-44
} 
2. A study aimed at building aprogram to develop the scientific and future dimension of kindergarten teachers.

Keywords: Kindergarten, Dimensions of Education, Parameters and Education.

\title{
أبعاد التربية المستقبلية لمعلمات رياض الأطفال
}

\author{
بان محمود
}

ملخص

إنّ التربية المستقبلية او رؤية المستقبل في التعليم بانه يحتل موقفا اساسيا في عملية التغير المجتمع البشري؛

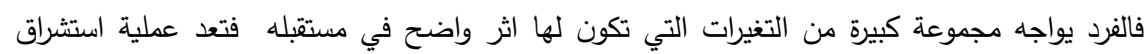

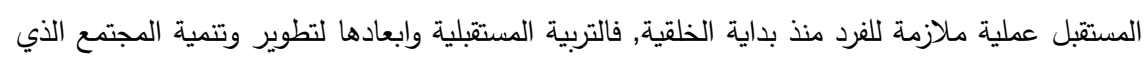

يصبو للتقدم فيعتبر التعليم اساسي, فالتربية سواء بصفتها متغيرا للتحول المجتمعي او محركا اوليا لهذا

التحول فهي بحكم دورها وطبيعتها اكثر جوانب المتمع عرضة للتغير وبناء على ذلك فالمتغيرات الحادة

التي التي ينطوي عليها المستقبل وما يفرضه من تحديات ستحدث بالضرورة تغيرات عنيفة في منظومة

التربية وفلسفتها وسياستها ودورها ومؤسساتها ومناهجها واساليبها.

وقد هدف البحث الحالي الى التعرف:

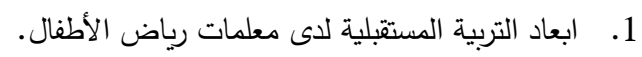

$$
\text { ولتحقيق الاهداف قامت الباحثة بما يلي: }
$$

1. تبنت مقياس ابعاد التربية المستقبلية (وريوش) 2019 المتكون من (64) فقرة وقد تحققت الباحثة

من القوة التميزية والتتساق الداخلي، واستخرجت الباحثة الثبات بطريقة الفا كرونباخ فقد بلغت

$$
\text { وخلصت نتائج البحث الى ان: }
$$

1. معلمات رياض الاطفال لا يتمتعن بالبعد العلمي والمستقبلي حيث كان الفرق غير دال

$$
\text { اوصتائيا. }
$$

1. دور وزارة التربية تشجيع وتعزيز معلمات رياض الاطفال من خلال توفير كافة

$$
\text { المستلزمات والامكانيات التي تساعدهن في تعليم الأطفال. }
$$

2. العمل على الاهتمام بكافة الابعاد المستقبلية للمعلمات.

$$
\text { توصلت الباحثة الى بعض المقترحات: }
$$

1. دراسة مماثلة على طلاب الجامعة بكافة التخصصات ولكلا الجنسين ذكور - اناث.

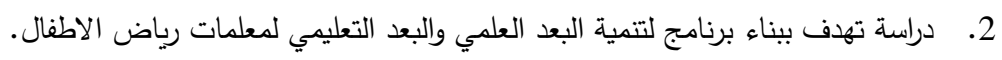

2 الدكتور : بان اسماعيل محمود، مديرية تربية بغداد الرصافة الأولى، وزارة التربية، العراق.

\section{IJHER}

International Journal of Humanities and Educational Research

Volume 2, Issue 2, June 2020, p.23-44 
الكلمات المفتاحية: رياض الاطفال، أبعاد التربية، المعلمات والتربية.

الفصل الأول: التعرف بالبحث

أولاً: مشكلة البحث:

لقد أمسى استثراق التربية المستقبلية او رؤية المستقبل في التعليم بأنّه يحتل موقفا اساسيا في عملية التغيير

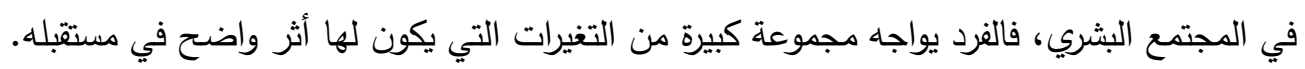

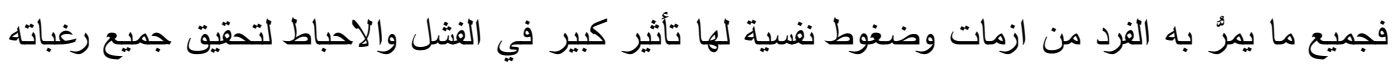

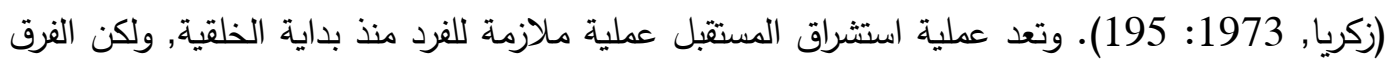

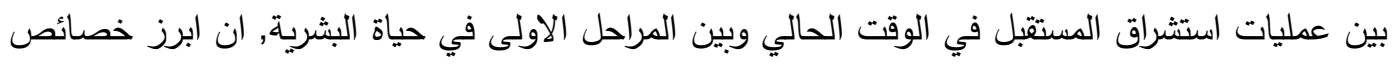

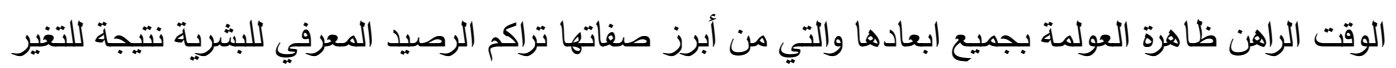

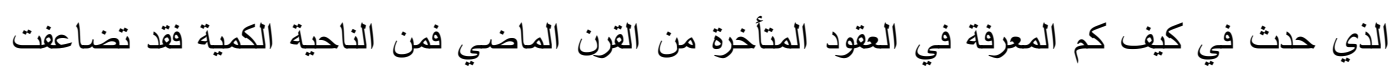

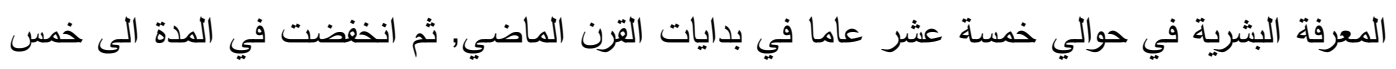

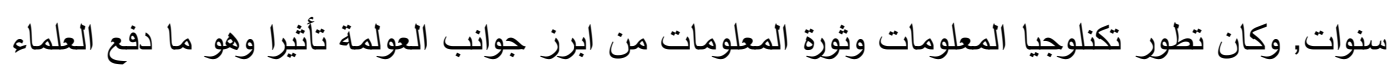
والمفكرين الى اهتمام بالمستقبل والتربية المستقبلية (حبيب,1988: 38). ويعد دور المعلمة مهم جدا في هذهات المرحلة فلها تأثير على تتشئة الطفل وتطوير شخصيته، فمن خلال عمل الباحثة كمديرة في أحد الرياض، الرئة فلاحظت قلة الاختصاص الدقيق لمعلمات رياض الاطفال، كثير من المعلمات يفتقرن الى اسس الس الارشاد

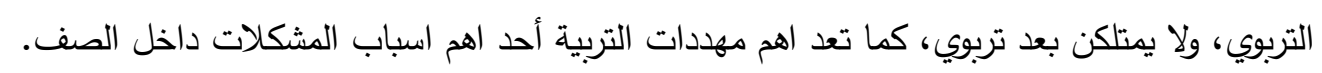
ثانياً: اهمية البحث:

تبرز اهمية البحث من اهمية التربية المستقبلية وابعادها في كونها الباب الرئيسي لتطوير وتتمية المجتمع الذي

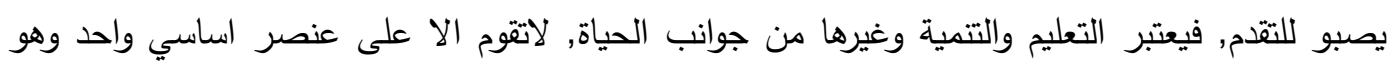

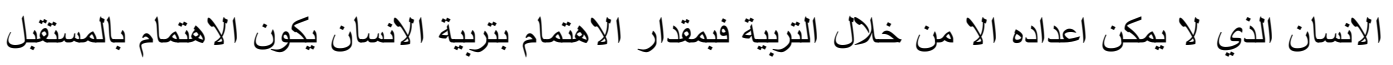

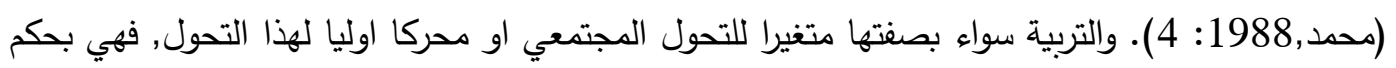

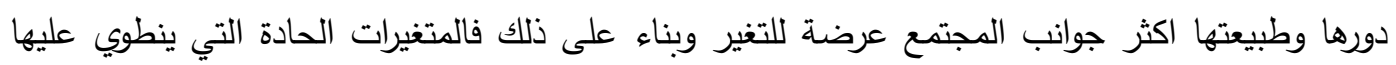
المستقبل وما يفرضه من تحديات ستحدث بالضرورة هزات عنيفة في منظومة التربية وفلسفتها وسياستها

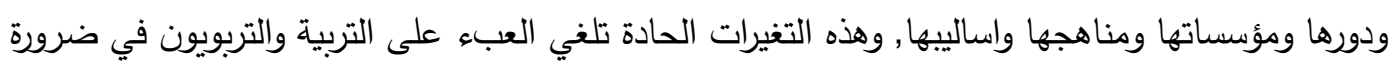

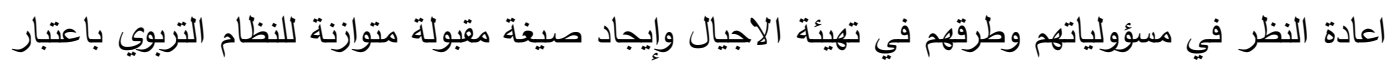

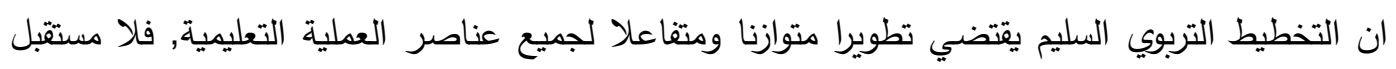
بدون تربية, ولا تربية بدون النظر في كل من حاجات المتعلمين ومتطلبات المجتمع المستقبلية, فالأمم التي لتي

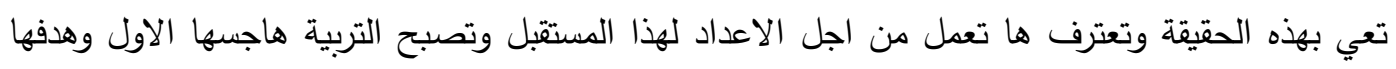

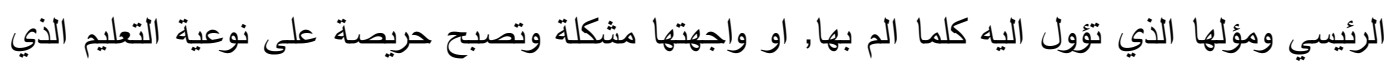
يتلقاه ابناؤها وتبحث لهم عن التقدم الحاضر في ميدان العلم وتسعى من اجل رفع مستوى التعليم الذي يلحقون نوته

\section{IJHER}

International Journal of Humanities and Educational Research

Volume 2, Issue 2, June 2020, p.23-44 
به لان الانسان هو اداة التغيير في الحاضر وفي المستقبل (كامل, 1987: 7). وللوصول لهذا البناء المستقبلي فلا بد ان تكون معلمة رياض الاطفال ملمة بجميع جوانب النمو , حيث تشترك المعلمة مع الاسرة

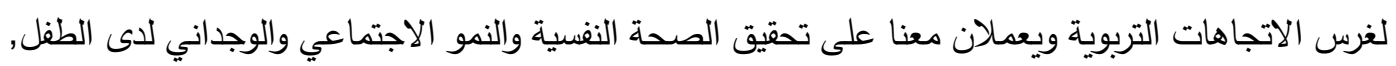
من خلال علاقتها بالطفل والاسرة وتبقى العلاقة بين المؤسسة الروضة وبين البيئة الاسرة علاقة تكاملية

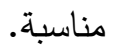

وتتجلى اهمية البحث بالنقاط الاتية:

1. نحن نعيش بعصر التطور في جميع المجالات, ويعود هذا التطور السبب الرئيسي لتحسين من مسؤوليات

المتعلمين وكذلك اهتمام المعلمات بالأبعاد التربوية.

2. يركز البحث الحالي على معلمة الروضة, حيث تعتبر الموجه الاول في هذه المرحلة العمرية المهمة

والخطرة بالنسبة للمجتمع.

3. يعد هذا البحث من البحوث المهمة لاهتمامه بمستقبل التربية بشكل عام.

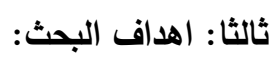

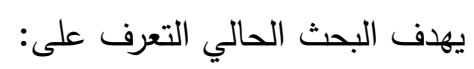

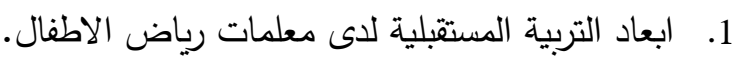

رابعا: حدود البحث:

يتحدد البحث الحالي بمعلمات رياض الاطفال لمديرية تربية بغداد الرصافة الاولى والثانية للعام الدراسي

.2020-2019)

خامساً: تحديد المصطحات:

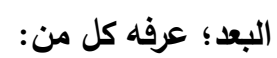

1. عبد الخالق 1983: الاثر الناتج عن احداث شيء معين لظاهرة ما سواء كانت مستقرة ام غير مستقرة

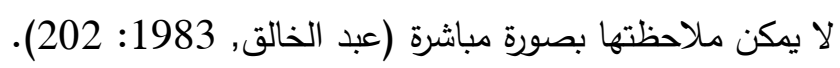

2. محمد علي 1996: الابتعاد وعدم التقارب لجملة من المعطيات والدلالات والاثار الغير ملموسة ولا يمكن

مشاهدتها والاطلاع على تفصيلاتها (محمد علي, 1996: 18 18).

التربية المستقبلية عرفها كل من:

1. زاهر 1990: مشروع حضاري تتموي يهدف الى تكوين الانسان عقليا ومهاريا وتتمية وعيه بذاته وتعزيز

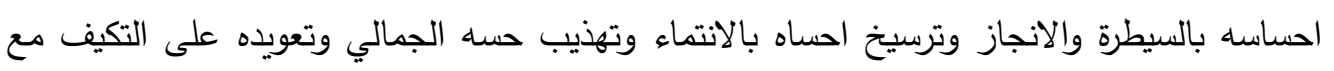

التغيير وتتمية الابداع لديه, ووعيه واحساسه بالمواطنة وتحقيق التوازن بين عالمه الداخليخ والخلي والخارجي

(زاهر , 1990)

2. موران 2002: هو تحقيق جميع التغيرات الفكرية العميقة والتي طور مهارة عامة قادرة على استثمار

السياق الثمولي بطريقة متعددة الابعاد والوعي بالية التعامل مع المستقبل لتمنح لكل فرد الامكانية

\section{IJHER}

International Journal of Humanities and Educational Research

Volume 2, Issue 2, June 2020, p.23-44 
الضرورية لرسم صورة مستقبلية لنفسه ولمجتمعه وللبشرية كافة لمواجهة التغيرات والتحويلات المتسارعة

$$
\text { واللامتوقعة (موران,2002: 13) }
$$

هي الدرجة الكلية التي تحصل عليها معلمات رياض الاطفال عند اجابتهن عن فقرات مقياس التربية المستقبلية الذي تبنته الباحثة.

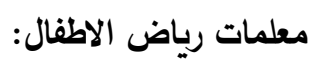

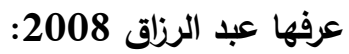

هي التي تقوم بإدارة العملية التعليمية والتربوية وبديلة للام وغيرها من الوظائف الأخرى، (عبد الرزاق,2008: (52). (20)

الفصل الثاني: الاطار النظري والدراسات السابقة

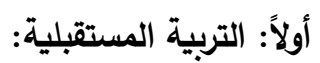
يعد التنكير من اهم الامور التي تميز الانسان عن باقي المخلوقات, حيث يهتم الكائن الحي بالتغيرات التي

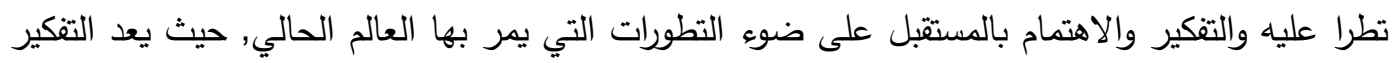

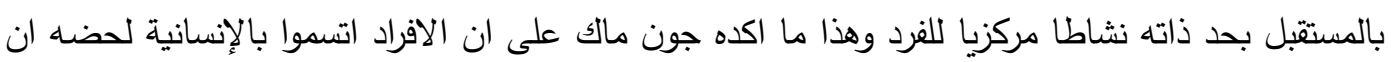

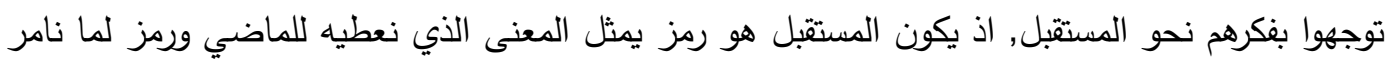

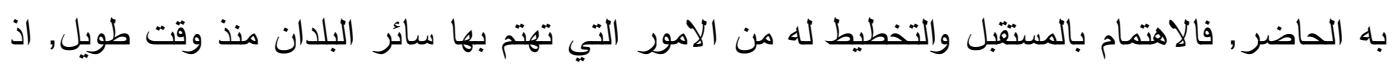
انشغلت المجتمعات المعاصرة ولاسيما المتقدمة بحاضرها ومستقبلها وصار المستقبل علما له نظرياته ومناهجه وتقنياته, ويجب ارتياد افاقه للتعرف على ماذا ستكون ومن هنا جاءت تسمية العصر الذي نعيشه بعصر

$$
\text { التفكير المستقبلي (النوري, 1992: 19: 112). }
$$

فالفرد ينظر دائما الى التطوير والتغيير للاستشراف بالمستقبل بما يحمله من تقدم حديث, وهذا يسبب له القلق, ويجعله كثير التفكير امام مستقبله ومواجهته (عامر ,2016: 1: 1). فلابد التخطيط الى احداث التغيير في الظروف المحيطة والنظرة التي تهدف الى التتبؤ باحتياجات المستقبل

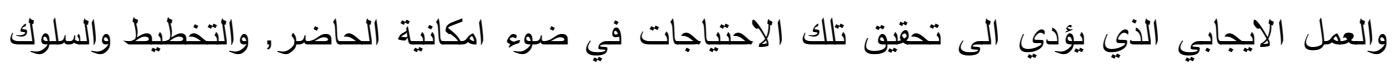

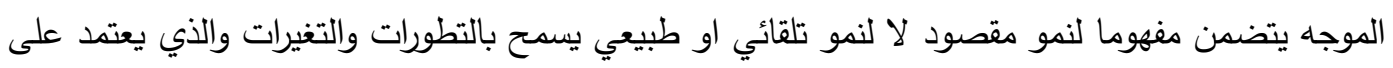

$$
\text { تكيف النظام (ستراك,2010: 1 1). }
$$

وتعد التربية المستقبلية وسيطا هدفها قيادة الفرد الى نقطة لا تحتاج بعدها الى وسيطا, فالتربية تكتمل عندما

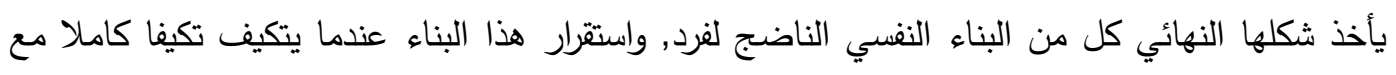
البيئة التي يعيش بها, فان جوهر الحياة النفسية وينبوع انطلاقها هما دوما تمثل نزعته الى ان يعطي ذاتهاء لئه

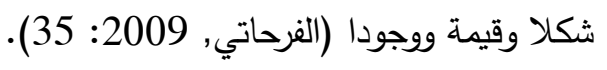

\section{IJHER}

International Journal of Humanities and Educational Research

Volume 2, Issue 2, June 2020, p.23-44 


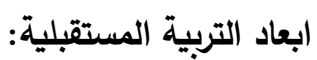

1. البعد التربوي: إنّ عملية التربية تعني تتمية الثخصية وتأهيل الفرد وبنائه من اجل تحقيق البعد الانساني

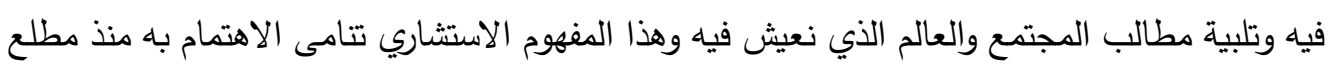
القرن الحادي والعشرين الذي شها ثورات في مجال المعرفة والعلوم وتأثيراتها على جوانب الحياة ولن

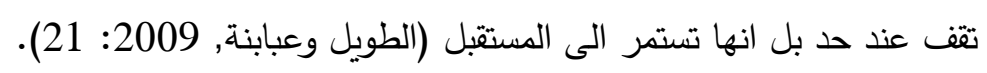

حيث يحتاج عصرنا الحالي الى تربية غير تقليدية تحتاج الى الوقوف على رؤى مستقبلية فلابد من

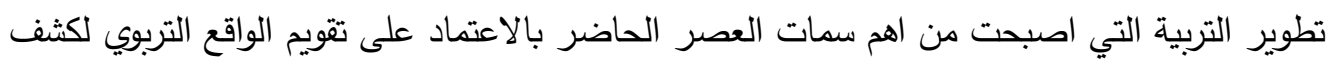
ما يعتريها من ضعف وما يعترضها من مشكلات والوصول الى حلول علمية (صابر , 2018: 121).

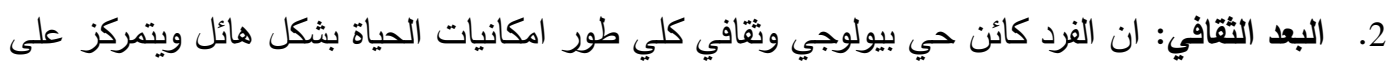

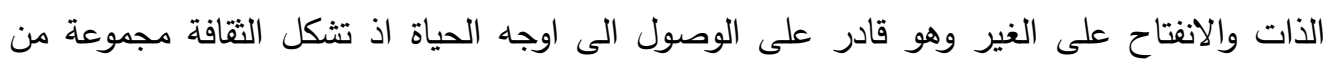
المعارف والقواعد والضوابط والخبرات والممنوعات والاستراتيجيات والمعتقدات والافكار والقيم والاساطير

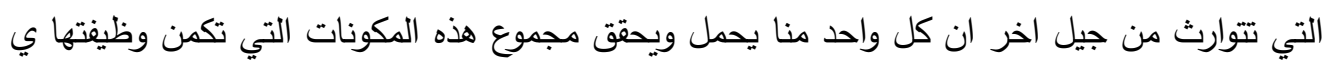
توجيه لمجتمع والحفاظ عليه بوصفه مركبا نفسيا واجتماعيا فلا وجدود لأي مجتمع قديما كان ام معاصرا

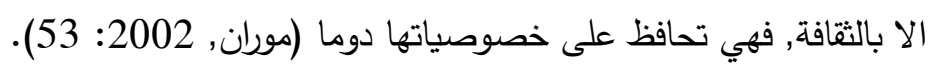
3. البعد الاخلاقي والاجتماعي: تتجاوز التغيرات الاجتماعية والابعاد المادية للمجتمع في الزمان والمكان التان

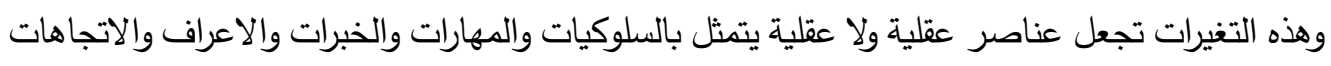
والتقاليد والتتظيمات الرسمية وغير الرسمية, ان هذا كله يؤثر في بعضه البعض ولات وفي وفي مسار التطور

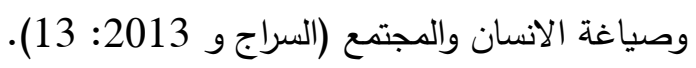

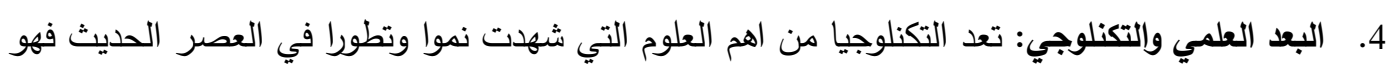

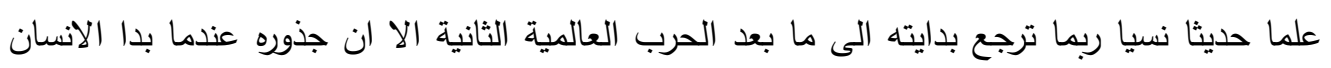
جاهدا الارتقاء به, وهذا ما أدى الى جميع الدول بالتخطيط التربوي والتعليمي كأداة للأفراد نحو العلم

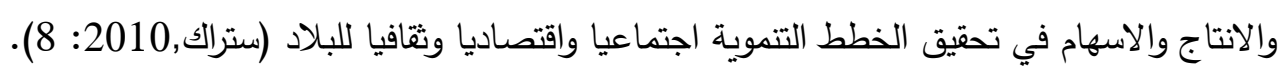
5. البعد المستقبلي: يعد التفكير بالمستقبل حاجة ملحة تعود لسرعة الحياة التي تعمل على تلاشي المستقبل

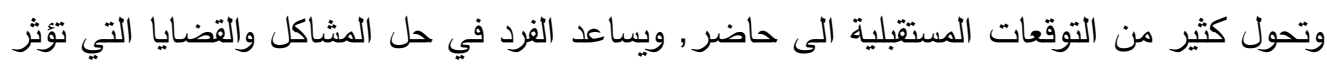
على التكيف مع ذاته والمجتمع, حيث يساعد التقكير المستقبلي على تتمية القدرة في التعامل مع التغيرات

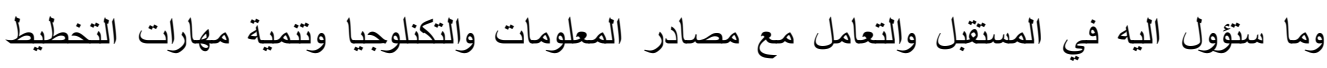
للمستقبل في جميع المجالات وتتمية الخيال والعقلية التي تتقبل التغيير والتحكم في مسارهم (السعدي,

(83: 2008

النظريات التي تناولت التربية المستقبلية:

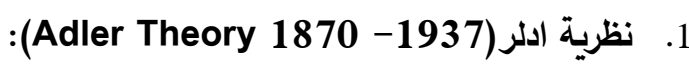

\section{IJHER}

International Journal of Humanities and Educational Research

Volume 2, Issue 2, June 2020, p.23-44 
يرى ادلر أنّ شعور الفرد بالنقص ينتج عنه شعور الكفاح من اجل التفوق الذي يدفع به الى محاولة للتغلب

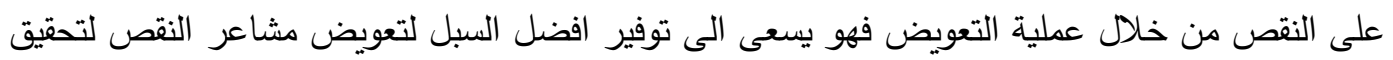

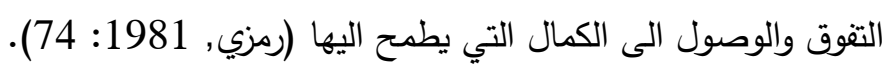
ان اي نقص عضوي او غير عضوي نفسي اجتماعي.... الخ يمكن تعويضه بالعمل والتدريب على سد هذا النقص وتقويته, وبعد النضال من اجل التفوق هو الاساس لطرح الحلول المكنة او المتاحة لمواجهة كافة لهن

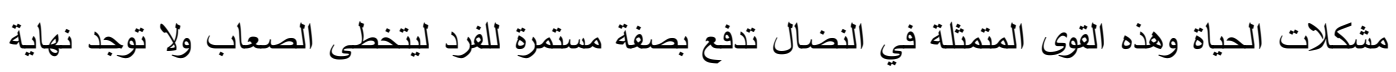
لهذا الحث والدفع, هنا يتسم بالاستمرارية فإنسان (ادلر) تحركه اهداف مستقبلية وتوقعاته واقتراحاته اكثر مما تحركه خبراته الماضية (داود والعبيدي, 1990: 167). وان القوى الخلاقة عند (ادلر) في تكوين حياة الفرد الخاصة هو اصراره بالنظر الى اهدافه المستقبلية وهيب

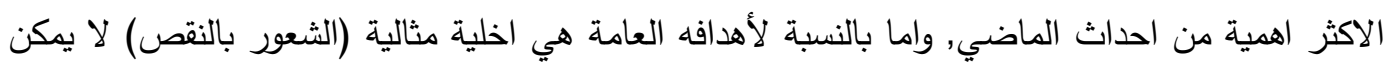

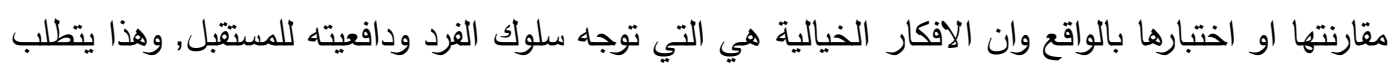
المزيد المزيد من الكفاح وانفاق الطاقة من اجل هذا الهدف الحيالي المثالي في الوصول التئل الى غالى غاياته واهدافه

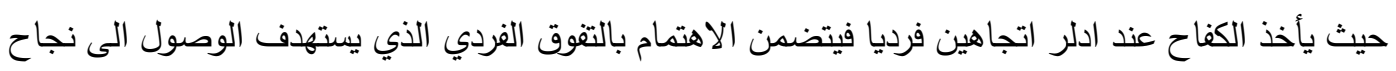

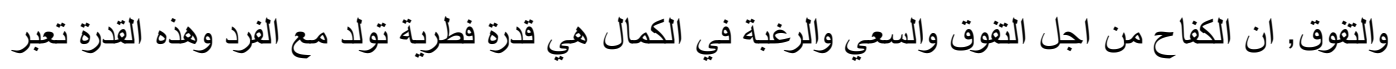

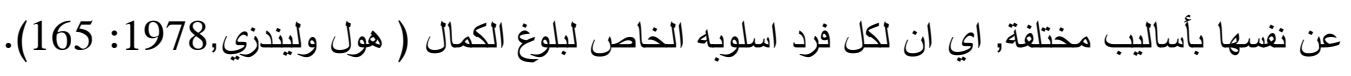
2. نظرية الحاجات (The Need theory 1937):

نظر ماسلو للفرد على انه متكامل, وربط بين حاجات الفرد والاضطرابات الذاتية التي تتشا له ليس كنتيجة لعدم اشباع الحاجات فحسب, بل نتيجة لنظرة الفرد للمستقبل, وان تحدي الرئيسي الذي يقف المات المام الفرد يمثل

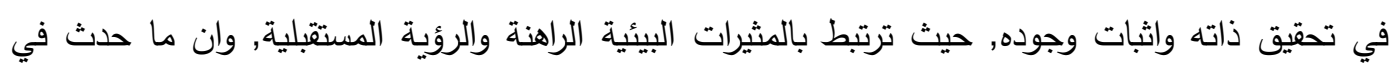
الماضي للفرد وما يتوقعه من احداث تهدد وجوده بثكل او باخر وتولد بداخله الخوف والتردد التي يزداد نتيجة الموازنة غير المتكافئة بيم امكانيات الفرد وما يفترض ان يكون للمستقبل, فقد رائم اسلو اننا لسنا ضحايا

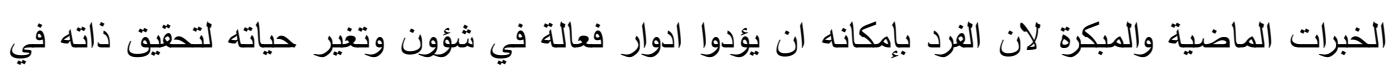
المستقبل, ولان اشباع الحاجات النفسية والفكرية والبايولوجية لا يكون بسبب الأوضاع الوان الراهنة وانما المستقبلية, لذا نجد ان ماسلو نظر نظرة متفائلة للفرد لما اعطاه من اهية في حياته للمستقبل ( الجعلي,1985: 65).

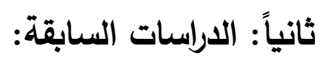

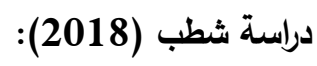

(التفكير المستقبلي والبيئة الابداعية المدركة وعلاقتها بما وراء الانفعال لاى طلبة الجامعة):

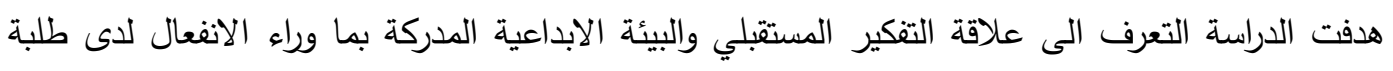
الجامعة تبعا لمتغيرات الجنس والتخصص, وتكونت عينة الدراسة من (400) طالب وطالبة, ولتحقيق اهداف التبه

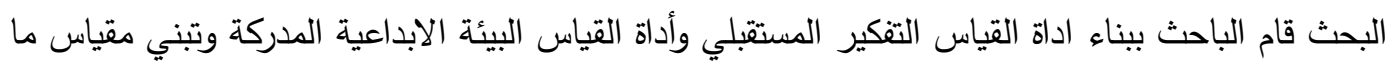

\section{IJHER}

International Journal of Humanities and Educational Research

Volume 2, Issue 2, June 2020, p.23-44 
وراء المعرفة الانفعال لجومان, واستعملت الوسائل الاحصائية لاختبار التائي لاستخراج القوة التميزية ومعامل ارتباط بيرسون لا يجاد ارتباط درجة الفقرة بالدرجة الكلية وتحليل التباين الثلاثي لإيجاد الفروق ذات الدلالة الاحصائية بين متغيرات البحث والفا كرونباخ لاستخراج الثبات, توصلت الدراسة الى ان طلبة البات الجامعة لديهم القدرة على التثكير المستقبلي نتيجة الخبرة المتراكمة والمكتسبة من التعليم والمواقف الحياتية, وتتأثر علاقة التفكير المستقبلي والبيئة الابداعية المدركة تبعا لمتغير الجنس والتخصص, ولا تتأثر علاقة التفكير المستقبلي ما وراء الانفعال تبعا لهذه المتغيرات (شطب الابن, 2018). دراسة وريوش (2019):

ابعاد التربية المستقبلية وعلاقتها بالوعي الذاتي والعجز المتعلم لاى طالبات قسم رياض الأطفال: هدفت الدراسة على التعرف على ابعاد التربية المستقبلية للطالبات والوعي الذاتي وعجز التعلم وعلاقة كل متغير مع بعظه لتحقيق اهداف البحث اعدت الباحثة مقياس التربية المستقبلية وطبق على عينة عددها (400) طالبة من قسم رياض الاطفال توصلت نتائج البحث على ان هناك فروق ذو دلالة احصائية على مقياس ابعاد التربية المستقبلية لمتغير المرحلة الدراسية.

\section{الفصل الثالث: منهجية البحث واجراء اته}

لتحقيق اهداف هذا البحث كان لابد من تحديد منهج البحث, وتحديد مجتمع البحث واختيار عينة ممثلة له واستخدام الادوات التي تتسم بالصدق والثبات والموضوعية وتطبيقها على العينة التي يتم اختيارها, ومن ثم لثمان تحليل البيانات, ومعالجتها احصائيا, والتوصل الى نتائج البحث في ضوء ذلك وسوف وليه يتم استعراض هذه الاجراءات في هذا الفصل وكما يأتي: أولاً: منهج البحث: ألخراء

استخدمت الباحثة المنهج الوصفي بوصفه انسب المناهج للدراسة من اجل تحليل الظاهرة المدروسة ووصفها, وتعتمد دراسة الظاهرة على ما توجد عليه في الواقع ويهتم بوصفها وصفا دقيقا فالمهمة الاساسية للوصف هي الونه ان تحقق الدراسة فهما افضل للظاهرة, حتى يتمكن من تحقيق تقدم في حل المشكلة ( ملحم, 2000: 32).

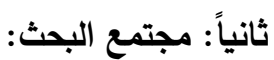
يقصد بالمجتمع هو جميع العناصر او المفردات ذات العلاقة بمشكلة البحث التي تسعى الباحثة الى ان تعمح عليها نتائج الدراسة ذات العلاقة بالمشكلة المدروسة (عباس وآخرون, 2009: 217). وقد تحدد مجتمع لعاد البحث الحالي بمعلمات رياض الاطفال لمدينة بغداد للعام الدراسي البالغ عددهن (1893) معلمة موزعين على رياض الاطفال وجدول (1) يبين ذلك.

\begin{tabular}{|c|c|}
\hline اعداد المعلمات & المديريات \\
\hline 397 & الرصافة الاولى \\
\hline 470 & الرصافة الثانية \\
\hline
\end{tabular}

\section{IJHER}

International Journal of Humanities and Educational Research

Volume 2, Issue 2, June 2020, p.23-44 


\begin{tabular}{|c|c|}
\hline 169 & الرصافة الثالثة \\
\hline 328 & كرخ اولى \\
\hline 334 & كرخ ثانثة \\
\hline 195 & المجموع \\
\hline 1893 & كالثة \\
\hline
\end{tabular}

يبين مجتمع البحث موزعين على رياض الاطفال الجدول رقم (1)

ثالثاً: عينة البحث:

عينة البحث هي مجموعة جزئية من مجتمع البحث, ممثلة لعناصر المجتمع افضل تمثيل, بحيث يمكن تعميم

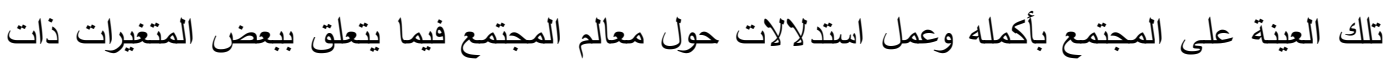
الصلة او الدراسة التي نحن بسبب التخطيط للقيام بها (عباس وآخرون,2009: 218). ولتحقيق اهداف البحث تطلب اختيار عينة التحليل الاحصائي واخرى للتطبيق النهائي وقد تم اختيارهم بالطريقة العشوائية الطبقية.

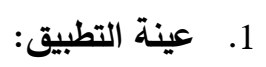
تم اختيار عينة التطبيق بالطريقة العشوائية بالتوزيع المتساوي, وقد توزعت بحسب المديريات بواقع (200)

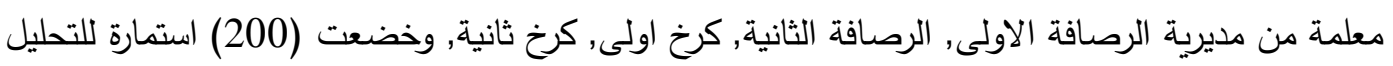
الاحصائي, اذ يثير هنريسون (Henrysoon,1971) ان حجم العينة المناسب في عملية التحليل الاحصائي لحساب القوة التميزية للفترات يفضل ان لا يقل عن (200) شخص يتم اختيارهم بدقة من المجتمع الاصلي (Henrysoon,1971;132), والجدول (2) يوضح ذلك.

\begin{tabular}{|c|c|}
\hline اعداد المعلمات & المديرية \\
\hline 50 & رصافة اولى \\
\hline 50 & رصافة ثانية \\
\hline 50 & كرخ اولى \\
\hline 50 & كرخ ثانية \\
\hline 200 & المجموع \\
\hline
\end{tabular}

حجم العينة موزعة حسب المديريات الجدول رقم (2)

2. العينة الاستطلاعية:

تكونت العينة الاستطلاعية من (50)معلمة من رياض الاطفال, تم اختيارهن بشكل عشوائي بالتوزيع المتساوي من مجتمع البحث, بواقع (15) معلمة من الرصافة الاولى, و(15) معلمة من الرصافة الثانية, و (10)

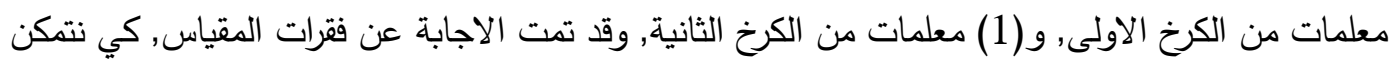

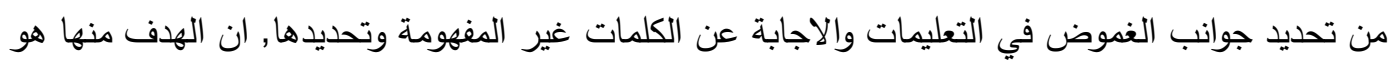

\section{IJHER}

International Journal of Humanities and Educational Research

Volume 2, Issue 2, June 2020, p.23-44 
التعرف على وضوح الفقرات والتعليمات من حيث الصياغة والمعنى, فضلا عن حساب الوقت المستغرق في الاجابة عنها عند تطبيقها على عينة البحث وبعد الانتهاء من الاجابة اتضح ان فقرات المقياس وتعليماته كانت مفهومة وواضحة لاى الطالبات.

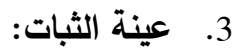

لحساب ثبات ادوات البحث الذي تم استخراجه بطريقة الفا كونباخ) اختيرت عينة عشوائية بلغ عددها (50) معلمة, بواقع (25) من الرصافة الاولى والثانية و(25)من الكرخ الاولى والثانية, وطريقة التجزئة النصفية. رابعاً: ادوات البحث:

بما ان البحث يهدف الى معرفة ابعاد التربية المستقبلية لمعلمات رياض الاطفال, تطلب الامر توفير استبانة لتحقيق الاهداف, لذا ارتأت الباحثة من تبني مقياس وريوش (2019), وبما ان المقياس حديث فلا ضرورة لاستخراج الصدق الظاهري والقوة التميزية. تصحيح المقياس:

لحساب الدرجة التي تحصل عليها الطالبة من خلال الإجابة عن فقرات المقياس وضعت الدرجات المناسبة لكل الفرات موزعة على بدائل المقياس التي تم تحديدها في ضوء الدراسات السابقة وطبيعة العينة, كانت بدائل الاجابة لمقياس استراتيجيات التعلم العميق والسطحي هي (موافق بثدة, موافق, موافق الى حد ما, غير موافق, غير موافق بشدة) وقد اعطيت عند التصحيح اوزان (1,2,3,4,5) ملحق (2) يبين المقياس بصورته النهائية. التحليل الاحصائي للفقرات:

ان الهدف الاساس من تحليل الفقرات هو الحصول على بيانات يحسب على وفقها القوة التميزية لفقرات المقياس, ومدى قدرة الفقرة على قياس ما اعدت لقياسه, اذ ان دقة المقياس تعتمد الى حد كبير الدقة في فقراته (Ebel,1972;392). ان التحليل الاحصائي للفقرات هو اكثر اهمية من التحليل المنطقي لأنه يكثف مدى ارتباط الفقرة ظاهريا بالسمة المراد قياسها ويكون اكثر صدقا وثباتا (عودة, 1998: 388). فضلا عن ذلك فان التحليل الاحصائي للفقرات ضروري للتميز بين الافراد اذ لابد من استبعاد الفقرات التي لا تمييز المجيبة, وابقاء الفقرات التي تمييز بينهم ولحساب خاصية التمييز والصدق لفقرات استراتيجية التعلم العميق والسطحي طبق على عينة مكونة من (200) طالبة اختيرت بالطريقة الطبقية العشوائية بالتوزيع المتساوي بحسب المراحل, ويبدو هذا الحجم مناسب للتحليل الاحصائي للفقرات.

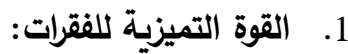
يقصد بالقوة التميزية للفقرات مدى قدرتها على التمييز بين ذوي المستويات العليا وذوي المستويات الدنيا بين الافراد بالنسبة لتلك للسمة (Grounlund,1970;253).

\section{IJHER}


وبعد حساب القوة التمييزية للفقرات من اهم الخصائص للمقاييس النفسية والتربوية لأنها تؤثر على قدرة المقياس في الكشف عن الفروق الفردية بين الافراد (Ebel,1972;398). اما الهدف من حساب القوة التمييزية للفقرات هو ضرورة ابقاء الفقرات ذات القوة التمييزية في الصورة النهائية للمقياس واستبعاد الفقرات غير المتميزة (Ghiselli,et.al,1981;434). ولحساب القوة التمييزية لفقرات المقياس اعتمدت الباحثة الاتي: اسلوب المجموعتين المتطرفتين: تم اختيار مجموعتين متطرفتين من الافراد ضمن هذا الاسلوب اعتمادا على لعى لونى الدرجات الكلية التي حصلوا عليها في المقياس ومن ثم تحليل كل فقرة من فقرات المقياس باستعمال الاختبار

التائي (T-test) لاختبار دلالة الفرق بين متوسطي المجموعتين العليا والدنيا ( عطية, 2001: 235). ولغرض تطبيق هذا الاسلوب اتبعت الباحثة الخطوات الاتية: طبق مقياس التربية المستقبلية بصورته الاولية بعد اجراء الصدق الظاهري حيث بلغ عدد فقراته (65) فقرة على عينة التميز البالغة (200)معلمة من رياض الاطفال, ثم اختيارهم بالطريقة العشوائية الطبقية ذات التوزيع المتساوي.

تصحيح اجابات المعلمات وتحديد الدرجة الكلية التي حصل عليها الطفل في كل استمارة. ترتيب الدرجات الكلية التي حصلت عليها افراد العينة بعد التصحيح ترتيبا تتازليا وعلى هذا الاساس

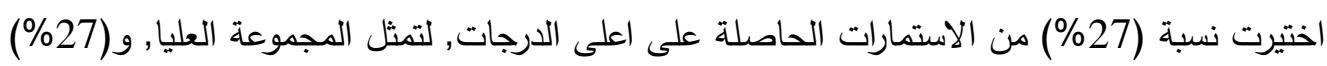

من الاستمارات الحاصلة على ادنى الدرجات لتمثل المجموعة الدنيا. تم استعمال الاختبار التائي (T-test) لعينيتين مستقلتين لمعرفة دلالة الفروق في درجات كل فقرة بين

المجموعتين العليا والدنيا, لأنّ القيمة التائية تمثل القوة التميزية للفقرة (Edwards,1957;159). وقد تم استعمال الحقيبة الاحصائية (Spss) والجدول (4) يوضح القوة التميزية لكل فقرة من فقرات المقياس, وجدول (3) يبين القوة التميزية.

\begin{tabular}{|c|c|c|c|c|c|c|c|c|}
\hline \multirow{2}{*}{ الاحصائية } & \multicolumn{2}{|c|}{ الاختبار التائي } & \multirow{2}{*}{ الحرجة } & \multirow{2}{*}{ الانحراف } & \multirow{2}{*}{ المستوسط } & \multirow{2}{*}{ العدد } & \multirow{2}{*}{ الفئة } & \multirow{2}{*}{ لفقرة } \\
\hline & الجدولية & المحسوبة & & & & & & \\
\hline \multirow[t]{2}{*}{ دالة } & 2.00 & 2.72 & 52 & 0.85 & 4.56 & 27 & عليا & 1 \\
\hline & & & & 1.22 & 3.78 & 27 & دنيا & \\
\hline \multirow[t]{2}{*}{ دالة } & 2.00 & 2.61 & 52 & 0.69 & 4.37 & 27 & عليا & 2 \\
\hline & & & & 1.14 & 3.70 & 27 & دنيا & \\
\hline \multirow[t]{2}{*}{ دالة } & 2.00 & 2.66 & 52 & 0.58 & 4.52 & 27 & عليا & 3 \\
\hline & & & & 1.17 & 3.85 & 27 & دنيا & \\
\hline \multirow[t]{2}{*}{ دالة } & 2.00 & 2.37 & 52 & 0.53 & 4.26 & 27 & عليا & 4 \\
\hline & & & & 1.45 & 3.56 & 27 & دنيا & \\
\hline \multirow[t]{2}{*}{ دالة } & 2.00 & 4.19 & 52 & 0.70 & 4.48 & 27 & عليا & 5 \\
\hline & & & & 1.24 & 3.33 & 27 & دنيا & \\
\hline
\end{tabular}

\section{IJHER}

International Journal of Humanities and Educational Research

Volume 2, Issue 2, June 2020, p.23-44 


\begin{tabular}{|c|c|c|c|c|c|c|c|c|}
\hline دالة & 2.00 & 3.31 & 52 & 0.64 & 4.41 & 27 & عليا & 6 \\
\hline & & & & 1.04 & 3.63 & 27 & دنيا & \\
\hline \multirow[t]{2}{*}{ دالة } & 2.00 & 2.69 & 52 & 0.72 & 4.15 & 27 & عليا & 7 \\
\hline & & & & 1.15 & 3.44 & 27 & دنيا & \\
\hline \multirow[t]{2}{*}{ دالة } & 2.00 & 3.24 & 52 & 0.71 & 4.26 & 27 & عليا & 8 \\
\hline & & & & 1.50 & 3.22 & 27 & دنيا & \\
\hline \multirow[t]{2}{*}{ دالة } & 2.00 & 3.33 & 52 & 0.78 & 4.30 & 27 & عليا & 9 \\
\hline & & & & 1.35 & 3.30 & 27 & دنيا & \\
\hline \multirow[t]{2}{*}{ دالة } & 2.00 & 2.15 & 52 & 1.03 & 4.15 & 27 & عليا & 10 \\
\hline & & & & 1.12 & 3.52 & 27 & دنيا & \\
\hline \multirow[t]{2}{*}{ دالة } & 2.00 & 3.23 & 52 & 0.58 & 4.22 & 27 & عليا & 11 \\
\hline & & & & 0.98 & 3.52 & 27 & دنيا & \\
\hline \multirow[t]{2}{*}{ دالة } & 2.00 & 3.19 & 52 & 0.75 & 4.22 & 27 & عليا & 12 \\
\hline & & & & 1.24 & 3.33 & 27 & دنيا & \\
\hline \multirow[t]{2}{*}{ دالة } & 2.00 & 2.91 & 52 & 0.78 & 4.07 & 27 & عليا & 13 \\
\hline & & & & 1.23 & 3.26 & 27 & دنيا & \\
\hline \multirow[t]{2}{*}{ دالة } & 2.00 & 2.72 & 52 & 0.73 & 4.33 & 27 & عليا & 14 \\
\hline & & & & 0.95 & 3.70 & 27 & دنيا & \\
\hline \multirow[t]{2}{*}{ دالة } & 2.00 & 2.43 & 52 & 0.75 & 4.22 & 27 & عليا & 15 \\
\hline & & & & 1.40 & 3.48 & 27 & دنيا & \\
\hline \multirow[t]{2}{*}{ دالة } & 2.00 & 3.13 & 52 & 0.68 & 4.19 & 27 & عليا & 16 \\
\hline & & & & 1.38 & 3.26 & 27 & دنيا & \\
\hline \multirow[t]{2}{*}{ دالة } & 2.00 & 3.73 & 52 & 0.53 & 4.26 & 27 & عليا & 17 \\
\hline & & & & 1.23 & 3.30 & 27 & دنيا & \\
\hline \multirow[t]{2}{*}{ دالة } & 2.00 & 5.31 & 52 & 0.51 & 4.56 & 27 & عليا & 18 \\
\hline & & & & 1.16 & 3.26 & 27 & دنيا & \\
\hline \multirow[t]{2}{*}{ دالة } & 2.00 & 5.46 & 52 & 0.66 & 4.15 & 27 & عليا & 19 \\
\hline & & & & 1.16 & 2.74 & 27 & دنيا & \\
\hline \multirow[t]{2}{*}{ دالة } & 2.00 & 2.42 & 52 & 0.80 & 4.22 & 27 & عليا & 20 \\
\hline & & & & 1.19 & 3.56 & 27 & دنيا & \\
\hline \multirow[t]{2}{*}{ دالة } & 2.00 & 4.35 & 52 & 0.70 & 3.89 & 27 & عليا & 21 \\
\hline & & & & 1.33 & 2.63 & 27 & دنيا & \\
\hline \multirow[t]{2}{*}{ دالة } & 2.00 & 2.16 & 52 & 0.87 & 3.93 & 27 & عليا & 22 \\
\hline & & & & 1.35 & 3.26 & 27 & دنيا & \\
\hline دالة & 2.00 & 4.11 & 52 & 0.74 & 3.81 & 27 & عليا & 23 \\
\hline
\end{tabular}

\section{IJHER}

International Journal of Humanities and Educational Research Volume 2, Issue 2, June 2020, p.23-44 


\begin{tabular}{|c|c|c|c|c|c|c|c|c|}
\hline & & & & 1.09 & 2.78 & 27 & دنيا & \\
\hline \multirow[t]{2}{*}{ دالة } & 2.00 & 2.08 & 52 & 0.71 & 3.96 & 27 & عليا & 24 \\
\hline & & & & 1.09 & 3.44 & 27 & دنيا & \\
\hline \multirow[t]{2}{*}{ دالة } & 2.00 & 2.68 & 52 & 0.76 & 3.96 & 27 & عليا & 25 \\
\hline & & & & 1.22 & 3.22 & 27 & دنيا & \\
\hline \multirow[t]{2}{*}{ دالة } & 2.00 & 3.97 & 52 & 0.72 & 4.15 & 27 & عليا & 26 \\
\hline & & & & 1.21 & 3.07 & 27 & دنيا & \\
\hline \multirow[t]{2}{*}{ دالة } & 2.00 & 2.55 & 52 & 0.83 & 4.07 & 27 & عليا & 27 \\
\hline & & & & 1.35 & 3.30 & 27 & دنيا & \\
\hline \multirow[t]{2}{*}{ دالة } & 2.00 & 2.36 & 52 & 0.92 & 4.00 & 27 & عليا & 28 \\
\hline & & & & 1.14 & 3.33 & 27 & دنيا & \\
\hline \multirow[t]{2}{*}{ دالة } & 2.00 & 3.85 & 52 & 0.66 & 4.26 & 27 & عليا & 29 \\
\hline & & & & 1.35 & 3.15 & 27 & دنيا & \\
\hline \multirow[t]{2}{*}{ دالة } & 2.00 & 2.79 & 52 & 0.62 & 4.00 & 27 & عليا & 30 \\
\hline & & & & 1.46 & 3.15 & 27 & دنيا & \\
\hline \multirow[t]{2}{*}{ دالة } & 2.00 & 5.27 & 52 & 0.82 & 4.30 & 27 & عليا & 31 \\
\hline & & & & 1.07 & 2.93 & 27 & دنيا & \\
\hline \multirow[t]{2}{*}{ دالة } & 2.00 & 3.08 & 52 & 0.68 & 4.00 & 27 & عليا & 32 \\
\hline & & & & 1.12 & 3.22 & 27 & دنيا & \\
\hline \multirow[t]{2}{*}{ دالة } & 2.00 & 2.88 & 52 & 0.85 & 3.96 & 27 & عليا & 33 \\
\hline & & & & 1.28 & 3.11 & 27 & دنيا & \\
\hline \multirow[t]{2}{*}{ دالة } & 2.00 & 5.44 & 52 & 0.69 & 4.41 & 27 & عليا & 34 \\
\hline & & & & 1.19 & 2.96 & 27 & دنيا & \\
\hline \multirow[t]{2}{*}{ دالة } & 2.00 & 3.03 & 52 & 0.68 & 4.00 & 27 & عليا & 35 \\
\hline & & & & 1.29 & 3.15 & 27 & دنيا & \\
\hline \multirow[t]{2}{*}{ دالة } & 2.00 & 3.30 & 52 & 0.85 & 3.96 & 27 & عليا & 36 \\
\hline & & & & 1.11 & 3.07 & 27 & دنيا & \\
\hline \multirow[t]{2}{*}{ دالة } & 2.00 & 4.67 & 52 & 0.65 & 4.04 & 27 & عليا & 37 \\
\hline & & & & 1.29 & 2.74 & 27 & دنيا & \\
\hline \multirow[t]{2}{*}{ دالة } & 2.00 & 4.10 & 52 & 0.66 & 3.85 & 27 & عليا & 38 \\
\hline & & & & 1.19 & 2.78 & 27 & دنيا & \\
\hline \multirow[t]{2}{*}{ دالة } & 2.00 & 8.27 & 52 & 0.66 & 4.26 & 27 & عليا & 39 \\
\hline & & & & 1.21 & 2.07 & 27 & دنيا & \\
\hline \multirow[t]{2}{*}{ دالة } & 2.00 & 5.06 & 52 & 0.75 & 3.89 & 27 & عليا & 40 \\
\hline & & & & 1.19 & 2.52 & 27 & دنيا & \\
\hline
\end{tabular}

\section{IJHER}

International Journal of Humanities and Educational Research Volume 2, Issue 2, June 2020, p.23-44 


\begin{tabular}{|c|c|c|c|c|c|c|c|c|}
\hline دالة & 2.00 & 4.29 & 52 & 0.87 & 3.93 & 27 & عليا & 41 \\
\hline & & & & 1.31 & 2.63 & 27 & دنيا & \\
\hline \multirow[t]{2}{*}{ دالة } & 2.00 & 4.20 & 52 & 0.82 & 4.15 & 27 & عليا & 42 \\
\hline & & & & 1.59 & 2.70 & 27 & دنيا & \\
\hline \multirow[t]{2}{*}{ دالة } & 2.00 & 7.39 & 52 & 0.81 & 3.96 & 27 & عليا & 43 \\
\hline & & & & 0.99 & 2.15 & 27 & دنيا & \\
\hline \multirow[t]{2}{*}{ دالة } & 2.00 & 7.89 & 52 & 0.74 & 3.81 & 27 & عليا & 44 \\
\hline & & & & 1.06 & 1.85 & 27 & دنيا & \\
\hline \multirow[t]{2}{*}{ دالة } & 2.00 & 5.17 & 52 & 0.88 & 3.81 & 27 & عليا & 45 \\
\hline & & & & 1.34 & 2.22 & 27 & دنيا & \\
\hline \multirow[t]{2}{*}{ دالة } & 2.00 & 5.53 & 52 & 0.81 & 3.96 & 27 & عليا & 46 \\
\hline & & & & 1.22 & 2.41 & 27 & دنيا & \\
\hline \multirow[t]{2}{*}{ دالة } & 2.00 & 4.01 & 52 & 0.92 & 4.00 & 27 & عليا & 47 \\
\hline & & & & 1.58 & 2.59 & 27 & دنيا & \\
\hline \multirow[t]{2}{*}{ دالة } & 2.00 & 7.17 & 52 & 0.55 & 4.00 & 27 & عليا & 48 \\
\hline & & & & 1.25 & 2.11 & 27 & دنيا & \\
\hline \multirow[t]{2}{*}{ دالة } & 2.00 & 6.40 & 52 & 0.89 & 3.89 & 27 & عليا & 49 \\
\hline & & & & 1.17 & 2.07 & 27 & دنيا & \\
\hline \multirow[t]{2}{*}{ دالة } & 2.00 & 4.53 & 52 & 0.95 & 3.85 & 27 & عليا & 50 \\
\hline & & & & 1.56 & 2.26 & 27 & دنيا & \\
\hline \multirow[t]{2}{*}{ دالة } & 2.00 & 4.88 & 52 & 1.08 & 3.63 & 27 & عليا & 51 \\
\hline & & & & 1.36 & 2.00 & 27 & دنيا & \\
\hline \multirow[t]{2}{*}{ دالة } & 2.00 & 3.42 & 52 & 1.20 & 3.15 & 27 & عليا & 52 \\
\hline & & & & 1.11 & 2.07 & 27 & دنيا & \\
\hline \multirow[t]{2}{*}{ دالة } & 2.00 & 4.01 & 52 & 0.66 & 2.74 & 27 & عليا & 53 \\
\hline & & & & 0.83 & 1.93 & 27 & دنيا & \\
\hline \multirow[t]{2}{*}{ دالة } & 2.00 & 5.34 & 52 & 0.71 & 2.96 & 27 & عليا & 54 \\
\hline & & & & 0.82 & 1.85 & 27 & دنيا & \\
\hline \multirow[t]{2}{*}{ دالة } & 2.00 & 6.91 & 52 & 0.73 & 3.00 & 27 & عليا & 55 \\
\hline & & & & 0.80 & 1.56 & 27 & دنيا & \\
\hline \multirow[t]{2}{*}{ دالة } & 2.00 & 3.35 & 52 & 0.70 & 2.78 & 27 & عليا & 56 \\
\hline & & & & 1.06 & 1.96 & 27 & دنيا & \\
\hline \multirow[t]{2}{*}{ دالة } & 2.00 & 5.66 & 52 & 0.48 & 2.81 & 27 & عليا & 57 \\
\hline & & & & 0.86 & 1.74 & 27 & دنيا & \\
\hline دالة & 2.00 & 4.12 & 52 & 0.64 & 2.56 & 27 & عليا & 58 \\
\hline
\end{tabular}

\section{IJHER}

International Journal of Humanities and Educational Research Volume 2, Issue 2, June 2020, p.23-44 


\begin{tabular}{|c|c|c|c|c|c|c|c|c|}
\hline & & & & 0.92 & 1.67 & 27 & دنيا & \\
\hline \multirow[t]{2}{*}{ دالة } & 2.00 & 6.63 & 52 & 0.63 & 2.63 & 27 & عليا & 59 \\
\hline & & & & 0.64 & 1.48 & 27 & دنيا & \\
\hline \multirow[t]{2}{*}{ دالة } & 2.00 & 4.04 & 52 & 0.69 & 2.41 & 27 & عليا & 60 \\
\hline & & & & 0.85 & 1.56 & 27 & دنيا & \\
\hline \multirow[t]{2}{*}{ دالة } & 2.00 & 4.40 & 52 & 0.70 & 2.56 & 27 & عليا & 61 \\
\hline & & & & 0.78 & 1.67 & 27 & دنيا & \\
\hline \multirow[t]{2}{*}{ دالة } & 2.00 & 3.06 & 52 & 0.62 & 2.33 & 27 & عليا & 62 \\
\hline & & & & 0.87 & 1.70 & 27 & دنيا & \\
\hline \multirow[t]{2}{*}{ دالة } & 2.00 & 4.06 & 52 & 0.69 & 2.59 & 27 & عليا & 63 \\
\hline & & & & 0.96 & 1.67 & 27 & دنيا & \\
\hline \multirow[t]{2}{*}{ دالة } & 2.00 & 5.06 & 52 & 0.70 & 2.52 & 27 & عليا & 64 \\
\hline & & & & 0.70 & 1.56 & 27 & دنيا & \\
\hline
\end{tabular}

يبين القوة التميزية القوة التميزية الجدول رقم (3)

2. ارتباط درجة الفقرة بالدرجة الكلية لأبعاد التربية المستقبلية:

يعد صدق الفقرات مؤشرا على قدرتها لقياس المفهوم الذي يقيسه المقياس. وذلك من خلال ارتباط الفقرة بالمحك وحينما لا يتوفر محك خارجي فان الدرجة الكلية للمقياس هي افضل محك داخلي (Ansatasi;1988;201). وعليه حسب معامل الارتباط بين درجة الفقرة بالدرجة الكلية للبعد الذي ينتمي اليه مقياس ابعاد التربية المستقبلية, واستعملت الباحثة معامل ارتباط بيرسون كما موضحة بجدول (4).

\begin{tabular}{|c|c|c|c|c|c|c|}
\hline الاحصائية & علاقة الفقرة بالدرجة & علاقة الفقرة & الاحصائية & بالارجة الكلية & علاقة الفقرة & الفقرة \\
\hline دالة & 0.196 & 0.394 & دالة & 0.196 & 0.540 & 1 \\
\hline دالة & 0.196 & 0.376 & دالة & 0.196 & 0.614 & 2 \\
\hline دالة & 0.196 & 0.358 & دالة & 0.196 & 0.452 & 3 \\
\hline دالة & 0.196 & $\mathbf{0 . 3 9 7}$ & دالة & 0.196 & 0.589 & 4 \\
\hline دالة & 0.196 & 0.570 & دالة & 0.196 & 0.717 & 5 \\
\hline دالة & 0.196 & 0.462 & دالة & 0.196 & 0.684 & 6 \\
\hline دالة & 0.196 & 0.376 & دالة & 0.196 & 0.530 & 7 \\
\hline دالة & 0.196 & 0.472 & دالة & 0.196 & 0.695 & 8 \\
\hline دالة & 0.196 & 0.492 & دالة & 0.196 & 0.619 & 9 \\
\hline دالة & 0.196 & 0.321 & دالة & 0.196 & 0.518 & 10 \\
\hline دالة & 0.196 & 0.437 & دالة & 0.196 & 0.533 & 11 \\
\hline دالة & 0.196 & 0.463 & دالة & 0.196 & 0.637 & 12 \\
\hline
\end{tabular}

\section{IJHER}




\begin{tabular}{|c|c|c|c|c|c|c|}
\hline دالة & 0.196 & 0.450 & دالة & 0.196 & 0.722 & 13 \\
\hline دالة & 0.196 & 0.402 & دالة & 0.196 & 0.500 & 14 \\
\hline دالة & 0.196 & 0.371 & دالة & 0.196 & 0.631 & 15 \\
\hline دالة & 0.196 & 0.491 & دالة & 0.196 & 0.662 & 16 \\
\hline دالة & 0.196 & 0.512 & دالة & 0.196 & 0.750 & 17 \\
\hline دالة & 0.196 & 0.609 & دالة & 0.196 & 0.709 & 18 \\
\hline دالة & 0.196 & 0.664 & دالة & 0.196 & 0.765 & 19 \\
\hline دالة & 0.196 & 0.380 & دالة & 0.196 & 0.560 & 20 \\
\hline دالة & 0.196 & 0.568 & دالة & 0.196 & 0.679 & 21 \\
\hline دالة & 0.196 & 0.362 & دالة & 0.196 & 0.669 & 22 \\
\hline دالة & 0.196 & 0.527 & دالة & 0.196 & 0.655 & 23 \\
\hline دالة & 0.196 & 0.293 & دالة & 0.196 & 0.620 & 24 \\
\hline دالة & 0.196 & 0.399 & دالة & 0.196 & 0.625 & 25 \\
\hline دالة & 0.196 & 0.504 & دالة & 0.196 & 0.593 & 26 \\
\hline دالة & 0.196 & 0.376 & دالة & 0.196 & 0.476 & 27 \\
\hline دالة & 0.196 & 0.377 & دالة & 0.196 & 0.440 & 28 \\
\hline دالة & 0.196 & 0.477 & دالة & 0.196 & 0.607 & 29 \\
\hline دالة & 0.196 & 0.381 & دالة & 0.196 & 0.432 & 30 \\
\hline دالة & 0.196 & 0.661 & دالة & 0.196 & 0.784 & 31 \\
\hline دالة & 0.196 & 0.426 & دالة & 0.196 & 0.541 & 32 \\
\hline دالة & 0.196 & 0.419 & دالة & 0.196 & 0.616 & 33 \\
\hline دالة & 0.196 & 0.628 & دالة & 0.196 & 0.717 & 34 \\
\hline دالة & 0.196 & 0.431 & دالة & 0.196 & 0.556 & 35 \\
\hline دالة & 0.196 & 0.448 & دالة & 0.196 & 0.548 & 36 \\
\hline دالة & 0.196 & 0.568 & دالة & 0.196 & 0.603 & 37 \\
\hline دالة & 0.196 & 0.501 & دالة & 0.196 & 0.617 & 38 \\
\hline دالة & 0.196 & 0.743 & دالة & 0.196 & 0.638 & 39 \\
\hline دالة & 0.196 & 0.558 & دالة & 0.196 & 0.718 & 40 \\
\hline دالة & 0.196 & 0.492 & دالة & 0.196 & 0.680 & 41 \\
\hline دالة & 0.196 & 0.480 & دالة & 0.196 & 0.741 & 42 \\
\hline دالة & 0.196 & 0.720 & دالة & 0.196 & 0.728 & 43 \\
\hline دالة & 0.196 & 0.701 & دالة & 0.196 & 0.841 & 44 \\
\hline دالة & 0.196 & 0.543 & دالة & 0.196 & 0.709 & 45 \\
\hline دالة & 0.196 & 0.599 & دالة & 0.196 & 0.752 & 46 \\
\hline دالة & 0.196 & 0.445 & دالة & 0.196 & 0.639 & 47 \\
\hline
\end{tabular}

\section{IJHER}

International Journal of Humanities and Educational Research

Volume 2, Issue 2, June 2020, p.23-44 


\begin{tabular}{|c|c|c|c|c|c|c|}
\hline دالة & 0.196 & 0.681 & دالة & 0.196 & 0.760 & 48 \\
\hline دالة & 0.196 & 0.607 & دالة & 0.196 & 0.709 & 49 \\
\hline دالة & 0.196 & 0.449 & دالة & 0.196 & 0.715 & 50 \\
\hline دالة & 0.196 & 0.508 & دالة & 0.196 & 0.764 & 51 \\
\hline دالة & 0.196 & 0.380 & دالة & 0.196 & 0.624 & 52 \\
\hline دالة & 0.196 & 0.434 & دالة & 0.196 & 0.595 & 53 \\
\hline دالة & 0.196 & 0.528 & دالة & 0.196 & 0.760 & 54 \\
\hline دالة & 0.196 & 0.658 & دالة & 0.196 & 0.679 & 55 \\
\hline دالة & 0.196 & 0.328 & دالة & 0.196 & 0.685 & 56 \\
\hline دالة & 0.196 & 0.577 & دالة & 0.196 & 0.837 & 57 \\
\hline دالة & 0.196 & 0.492 & دالة & 0.196 & 0.752 & 58 \\
\hline دالة & 0.196 & 0.692 & دالة & 0.196 & 0.675 & 59 \\
\hline دالة & 0.196 & 0.473 & دالة & 0.196 & 0.770 & 60 \\
\hline دالة & 0.196 & 0.465 & دالة & 0.196 & 0.733 & 61 \\
\hline دالة & 0.196 & 0.348 & دالة & 0.196 & 0.708 & 62 \\
\hline دالة & 0.196 & 0.443 & دالة & 0.196 & 0.716 & 63 \\
\hline دالة & 0.196 & 0.543 & دالة & 0.196 & 0.828 & 64 \\
\hline
\end{tabular}

يبين معاملات الارتباط بين درجة الفقرة والدرجة الكلية للمقياس الجدول رقم (4)

مؤشرات الصدق والثبات لمقياس ابعاد التربية المستقبلية: صدق المقياس:

ان مفهوم الصدق من اكثر المفاهيم الاساسية اهمية في مجال المقاييس التربوية والنفسية ان لم يكن اهها جميعا وهو الذي يكثف قدرة المقياس لتادية الغرض الذي اعد من اجله (عودة, 1998: 340).

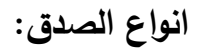
1. الصدق الظاهري: وهو الذي يظهر فيها المقياس مناسبا للغرض الذي وضع لاجله (ابو حويج واخرون, 2002: 134). وهو المظهر العام للمقياس او الصورة الخارجية له.

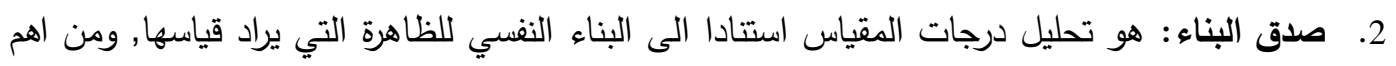

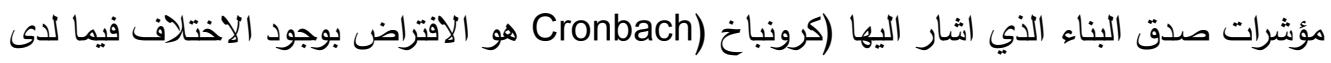

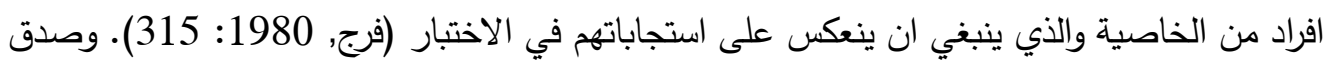

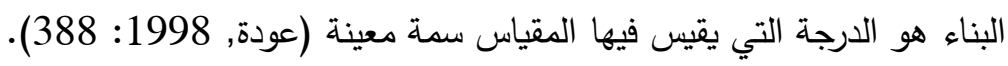
3. ثبات المقياس: وهو المدى لقياس الفقرات للمقدار الحقيقي للظاهرة التي تقاس والثبات يعني توافر الدقة

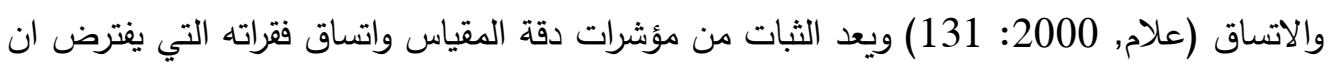
تقيس ما يجب قياسه, اي تظهر النتائج دقة عالية اذ اعيد تطبيقه على نفس المجموعة ولتهات

\section{IJHER}

International Journal of Humanities and Educational Research

Volume 2, Issue 2, June 2020, p.23-44 
(Kerlinge,1973; 29). ومن خلال حساب الثبات يتم تقدير الاخطاء المقياس واتباع طرق اخرى لتقليل الاخطاء وقد تحققت الباحثة من ثبات المقياس بطريقتين هما:

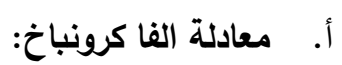

وتثير هذه الطريقة الى حساب الارتباطات بين درجات جميع فقرات المقياس على عد ان الفقرة عبارة عن مقياس قائم بحد ذاته, وانه يعد مؤشرا على التجانس بين فقرات المقياس (عودة, 1998:

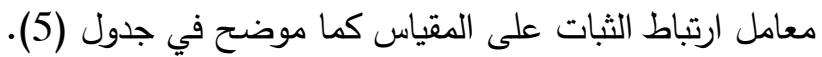

\begin{tabular}{|c|c|c|}
\hline عدد الفقرات & الفا كرومباخ & المجال \\
\hline 13 & 0.855 & التربوي \\
\hline 13 & 0.885 & الثقافي \\
\hline 13 & 0.838 & الأخلاقي \\
\hline 13 & 0.923 & العلمي \\
\hline 12 & 0.918 & المستقبلي \\
\hline 64 & 0.949 & المقياس ككل \\
\hline
\end{tabular}

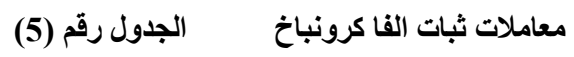

وهو معامل ثبات جيد يمكن الاعتماد عليه وفق معايير اصحاب الاختصاص في القياس النفسي في القول

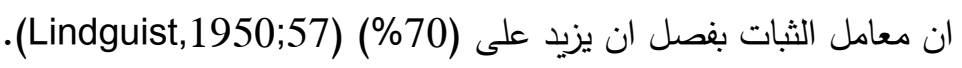

\section{الفصل الرابع: عرض النتائج ومناقشتها}

يتضمن هذا الفصل عرض وتفسير ومناقثة النتائج التي توصل اليها البحث الحالي بناء على الاطار النظري النيات ومناقشتها مع نتائج الدراسات السابقة, كما يتضمن تقديم عدد من التوصيات التي توصي بهات التها الباحثة. عرض النتائج في ضوء الاهداف وتنفيرها ومناقثتها: فيما يلي عرض نتائج البحث التي تم التوصل اليها في ضوه الاهدئ اهدافه, وسيتم عرضها: 1. التعرف على ابعاد التربية المستقبلية لمعلمات رياض الأطفال:

أ. البعد التربوي: تحقيقا لهذا البعد قامت الباحثة بتطبيق المقياس بصورته المهائية على افراد العينة البالغ عددها (200) معلمة, وبعد تحليل الدرجات تم استخراج المتوسط الحسابي الذي بلغ (155,50) وبانحراف معياري (6, 56), كما حسب المتوسط الفرضي (39) وباستخدام الاختبار التائي لعينة واحدة ظهر ان القيمة الدحسولبة البالغة ( 18, 072) وعند مقارنتها بالقيمة الجدولية (1,96) وندية مستوى دلالة (0,05) وعند درجة حرية (199), ظهر ان القيمة التائية المحسوبة اعلى من الجدولية

\begin{tabular}{|c|c|c|c|c|c|c|c|c|}
\hline \multirow{2}{*}{ الدلالة } & \multicolumn{2}{|c|}{ الاختبار التائي } & \multirow{2}{*}{ درجة } & \multirow{2}{*}{ معياري } & \multirow{2}{*}{ مسابي } & \multirow{2}{*}{ فرتوسط } & \multirow{2}{*}{ العينة } & \multirow{2}{*}{ البعد } \\
\hline & الجدولية & المحسوبة & & & & & & \\
\hline
\end{tabular}

\section{IJHER}

International Journal of Humanities and Educational Research

Volume 2, Issue 2, June 2020, p.23-44 


\begin{tabular}{|l|l|l|l|l|l|l|l|l|}
\hline التربوي & 1,96 & 18,072 & 199 & 6,56 & 50,85 & 39 & 200 & دالة \\
\hline
\end{tabular}

يوضح المتوسط الحسابي للبعد التربوي الجدول رقم (6)

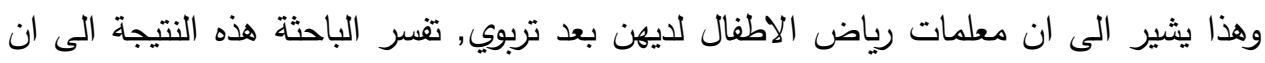

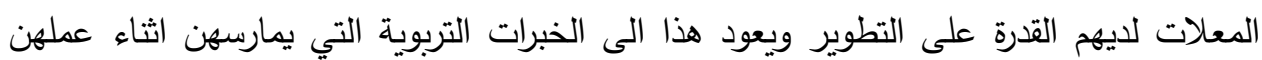
كمعلمات, استتادا الى الدورات والبرامج التي يطورن بهن من انفسهن. تتواف هذه النتيجة مع دراسة وريوش (2019). ب. البعد الثقافي: تحقيقا لهذا البعد قامت الباحثة بتطبيق مقياس ابعاد التربية المستبلية بصورته النهائية على افراد العينة البالغ عددهم (200) معلمة, وبعد تحليل الدرجات تم استخراج المتوسط الحسابي الذي بلغ $(48,36)$ وبانحراف معياري (7,10) كما حسب المتوسط الفرضي (39) وباستخدام الاختبار التائي لعينة واحدة ظهر ان القيمة التائية المحسوبة البالغة $(13,183)$ وعند مقارنتها بالقيمة الجدولية البالغ عددها $(1,96)$ عند مستوى دلالة $(0,05)$ ودرجة حرية (199) ظهر ان القيمة الدحسوبة اعلى من الجدولية وجدول (7) يوضح ذلك.

\begin{tabular}{|c|c|c|c|c|c|c|c|c|}
\hline \multirow{2}{*}{ الدلالة } & \multicolumn{2}{|c|}{ القيمة التائية } & \multirow{2}{*}{ الحربة } & \multirow{2}{*}{ الفرضي } & \multirow{2}{*}{ الانحراف } & \multirow{2}{*}{ الحسابي } & \multirow{2}{*}{ العينة } & \multirow{2}{*}{ البعد } \\
\hline & المحسوبة & الجدولية & & & & & & \\
\hline دالة & 1,962 & 13,183 & 199 & 39 & 7,10 & 48,36 & 200 & الثقافى \\
\hline
\end{tabular}

المتوسط الحسابي للبعد الثقافي الجدول رقم (7)

وهذا يثير الى المعلمات لديهن بعد ثقافي, تفسر الباحثة هذه النتيجة الى ان المعلمات لايهم خبرات

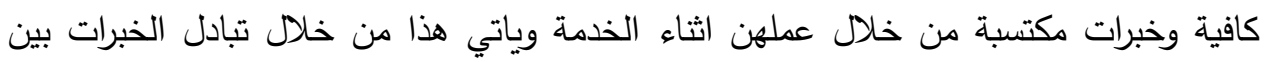

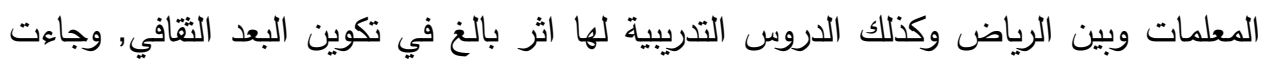
مطابقة مع دراسة (وريوش 2019).

ت. البعد الاخلاقي: تحقيقا لهذا البعد, فقد قامت الباحثة بتطبيق مقياس ابعاد التربية المستقبلية على

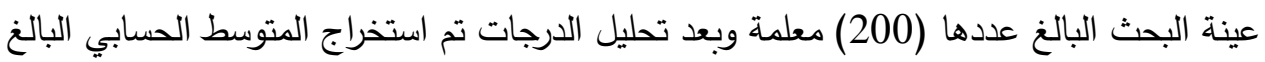
(46,23) وبانحراف معياري ( 6,53), كما حسب المتوسط الفرضي (29) (29), وباستخدام الاختبار

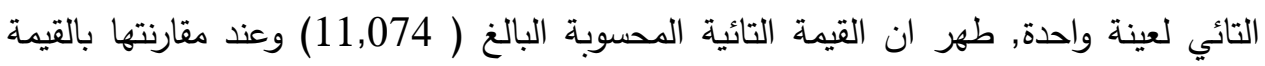
الجدولية (1,96) عند مستوى دلالة (0,05), ظهر ان القيمة المحسوبة اعلى من الجدولية وجدول

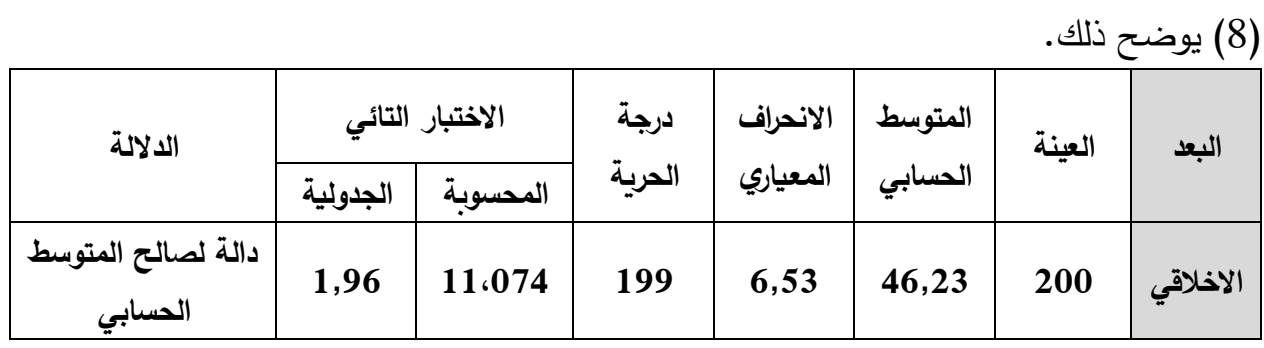

يوضح المتوسط الحسابي للبعد الاخلاقي الجدول رقم (8)

\section{IJHER}

International Journal of Humanities and Educational Research

Volume 2, Issue 2, June 2020, p.23-44 
ويشير هذا على ان المعلمات يمتلكن بعد اخلاقي ويأتي هذا لكون معلمة الروضة تمتلك صفات

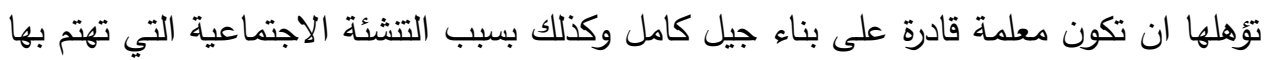

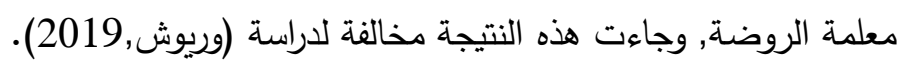

ث. البعد العلمي: تحقيقا لهذا البعد فقد قامت الباحثة بتطبيق مقياس ابعاد التربية المستتبلية على عينة البحث البالغ عددها (200) معلمة وبعد تحليل الدرجات تم استخراج المتوسط الحسابي ( 35,25$)$ وبانحراف معياري ( 8, 60), وكانت درجة الحرية (199) والمتوسط الفرضي (39) حيث الظهرت النتائج من خلال مقارنة القيمة التائية المحسوبة مع القيمة الجدولية البالغة ( 1 (4,358), وجدول (9) (9)

\begin{tabular}{|c|c|c|c|c|c|c|c|c|}
\hline \multirow{2}{*}{ الدلالة } & \multicolumn{2}{|c|}{ الاختبار التائي } & \multirow{2}{*}{ الحرية } & \multirow{2}{*}{ الفرضي } & \multirow{2}{*}{ المعياري } & \multirow{2}{*}{ الحسابي } & \multirow{2}{*}{ العينة } & \multirow{2}{*}{ البعد } \\
\hline & الجدولية & المحسوبة & & & & & & \\
\hline الدتوسط الفرضي & 1,96 & 4,358 & 199 & 39 & 8,60 & 35,25 & 200 & العلمي \\
\hline
\end{tabular}

يوضح المتوسط الفرضي والانحراف المعياري الجدول رقم (9)

ان المعلمات لا يمتلكن بعد علمي وجاءت هذه النتيجة مخالفة لدراسة وريوش 2019, حيث تفسر

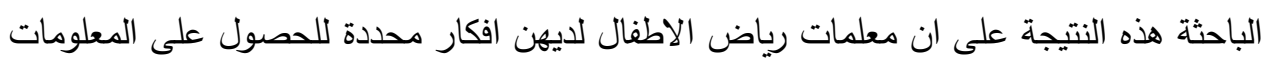

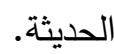

ج. البعد المستقبلي: تحقيقا لهذا البعد فقد قامت الباحثة بتطبيق مقياس ابعاد التربية المستتبلية على العينة المتكونة (200) معلمة, وبعد تحليل الدرجات تم استخراج المتوسط الحسابي الذي بلغ لئل 18,63) وبانحراف معياري (5,27), كما حسب المتوسط الفرضي ( 36 (36) وباستخدام الاختبار التائي لعينة واحدة ظهر قيمة التائية المحسوبة $(32,973)$ عند مقارنتها بالجدولية $(1,96)$ ان ان

\begin{tabular}{|c|c|c|c|c|c|c|c|c|}
\hline \multirow{3}{*}{ الاحصائية } & \multirow{2}{*}{\multicolumn{2}{|c|}{ القيمة التائية }} & \multirow{3}{*}{ الحرية } & \multirow{3}{*}{ الفرضي } & \multirow{3}{*}{ المعياري } & \multirow{3}{*}{ الحسابوي } & \multirow{3}{*}{ العينة } & \multirow{3}{*}{ البعد } \\
\hline & & & & & & & & \\
\hline & الجدولية & المحسوبة & & & & & & \\
\hline دالة لصالح & & & & & & & & \\
\hline المتوسط & 1,96 & 32,973 & 199 & 36 & 5,27 & 18,63 & 200 & المستقبلي \\
\hline الفرضي & & & & & & & & \\
\hline
\end{tabular}

يوضح المتوسط الحسابي الجدول رقم (10)

اي ان المعلمات لا يمتلكن بعد مستقبلي, اي ان المعلمات لا يطورن من وسائلهن التعليمية وليس

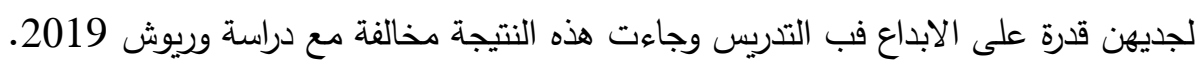

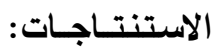

في ضوء نتائج البحث الحالي تستتتج الباحثة ما يأتي:

\section{IJHER}

International Journal of Humanities and Educational Research

Volume 2, Issue 2, June 2020, p.23-44 


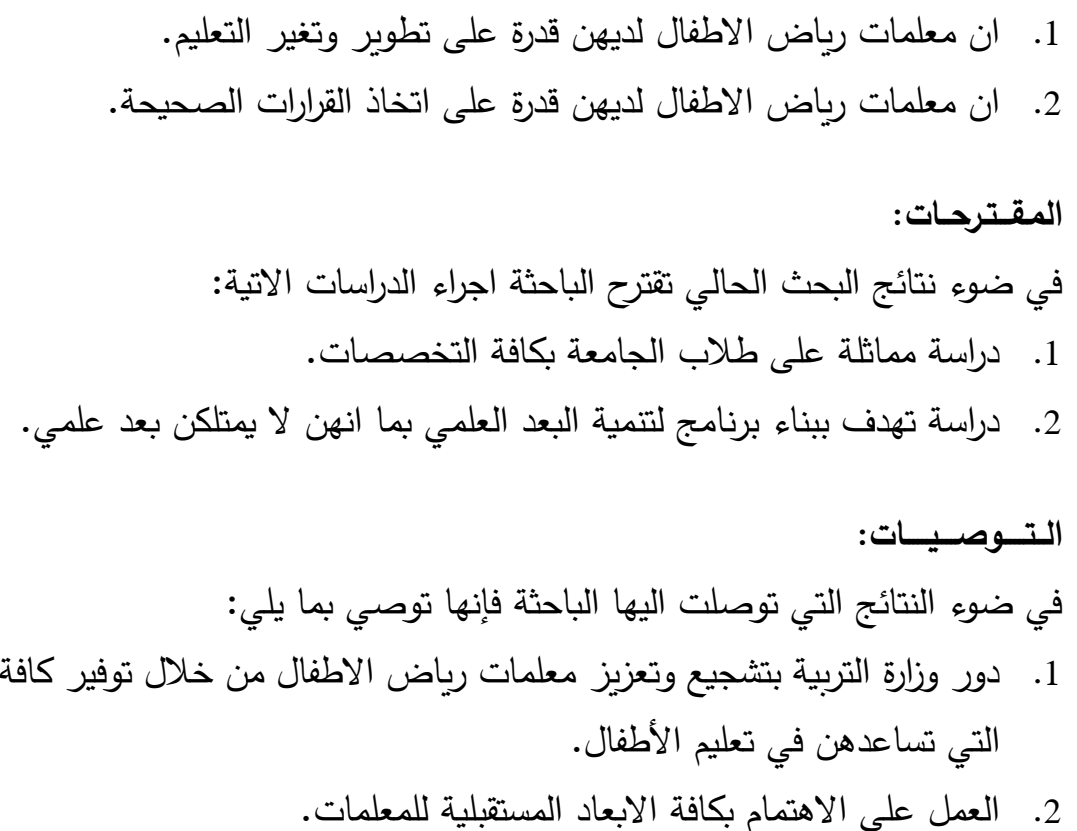

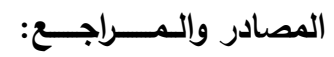

عودة, احمد سليمان (1998), القياس والتقويم في العملية التدريسية, ط2, دار الامل للنشر والتوزيع.

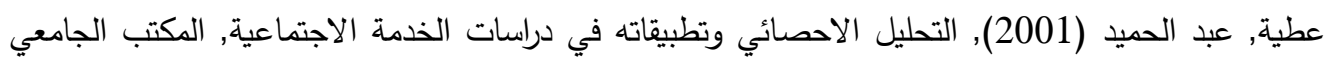

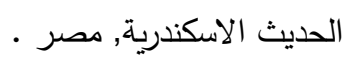

ابو حويج, مروان, واخرون (2002), القياس والتقويم في التربية وعلم النفس, ط2, دار العلمية الدولية للنشر والتوزيع, عمان الاردن.

علام, صلاح الدين محمود(2000), القياس والتقويم التربوي والنفسي اساسياته وتطبيقاته وتوجيهاته المعاصرة,ط1ر, دار الفكر , القاهرة. وريوش, سعدية موهي, (2019). ابعاد التربية المستقبلية وعلاقتها بالوعي الذاتي والعجز المتعلم لدى طالبات قسم رياض الاطفال, رسالة ماجستير غير منشورة, جامعة بغداد كلية التربية للبنات .

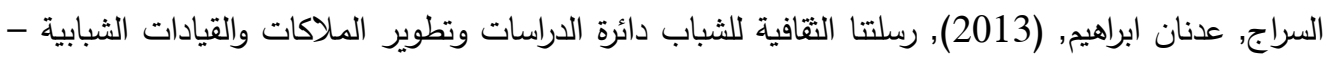

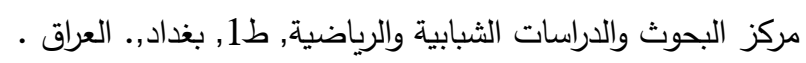
السعدي, جميل سعيد (2008), فعالية استخدام بعض الانثطة الاثرائية القائمة على اساليب استتزاف المستقبل.

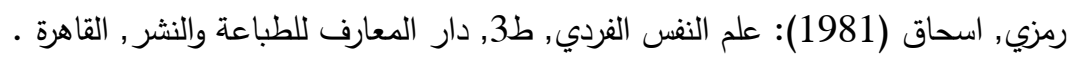

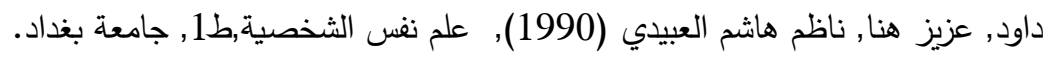
هول, ولندزي (1978), نظريات الثخصية: ترجمة فرج احمد فرج واخرون الهيئة الدصرية للنشر , التاهرة. الجعلي, محمد (1985), تسبب العاملين محاولة لتأطير ودراسة وطرح ظاهرة سلوكية, جامعة الدول العربية. شطب, انس اسود (2018) التنكير السنتقبلي والبيئة الابداعة المدركة وعلاقتها بما وراء. عباس, محمد خليل, وآخرون, 2009, مدخل مناهج البحث في التربية وعلم النفس, ط2, دار الميسرة للنشر .

\section{IJHER}

International Journal of Humanities and Educational Research

Volume 2, Issue 2, June 2020, p.23-44 
- ملحم مازن (2000), الثعور بالوحدة النفسية وعلاقتها بالعوامل الخمسة للشخصية دراسة ميدانية على عينة من

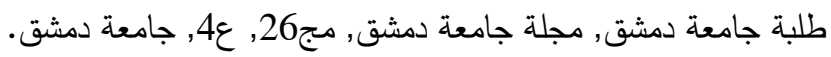
عبد الخالق, احمد محمد (1983), الابعاد الاساسية للشخصية, ط2, دار المعاد المعارف الجامعية الاسكندرية.

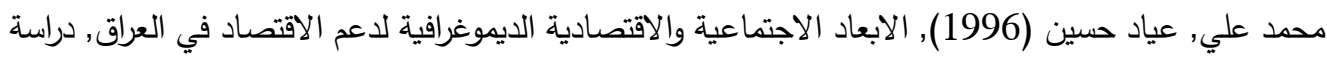
ميدانية, رسالة ماجستير غير منثورة كلية الآداب جامعة بغداد. زاهر , ضياء الدين (1990), كيف تنكر الثعوب العربية في تعليم المستقبل, ط1, منتدى الفكر العربي, عمان,

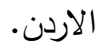

النوري, عبد الغني عبد الفتاح (1992) التخطيط لتطوير المناهج واهيته في دراسة المستقبل لتخطيط التتمية

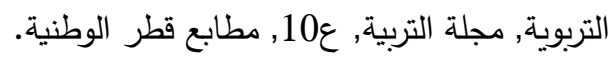
عامر , طارق عبد الرؤوف (2016) احتياجات المجتمع وتحديات المستقبل, ط1, دار اليازوري العلمية . ستراك, رياض (2010) التخطيط التربوي, ط1, بغداد, العراق. الفرحاتي, السيد محمود,( 2009), سلوك العجز المتعلم, الاكاديمي والعزو السببي لدى طلبة الجامعة في السياقات الفقيرة. الطويل, هاني عبد الرحمن, وصالح احدد امين, عبانية,(2009), المدرسة المتعلمة, مدرسة المستقبل, ط1, دار وائل للنشر , عمان, الاردن. صابر , محمد سميح ممدوح (2018), استراتيجيات علم النفس التربوي بين الواقع والمأمول, دار العلم والايمان للنشر والتوزيع, ط1, دسوق الجزائر.

- Anastasia,A\& Urbina(1988): Psychological Testing,Mcmillan publishing Company, New York.

- Eble,R.L(1972); Essentials of Education Measurementn, New,Jersey,prentice-Hall,Inc.

- Edwards,(1957) ; Technijues Of Attitude Scale Construction,New york Appleton Country Corfte.

- Gronbach,L.J(1970); Essentials of psychological testing 3d,New York;Harper.

- Henrysoon,(1971) Gathering, Analyzing,And Uising Data on Test Item in Educational Measurment Thorndike ; pepperdine University press.

- Kerlinge,F. n(1973) ; Foundation of Behavioral reswarch Education \& psychology rein hart \& Winston London.

- Lindjuist (1950); Educational Measurement Washinton,American Coancilon Education.

- Murphy, R.K(1988); Psychlogical testing principle and application ,A;;international, Inc, New York.

- Stanley, G.J\&Hopkins.K.D(1972) ;Educational psychologe Measurement and Evaluation, New jersey.

\section{IJHER}

International Journal of Humanities and Educational Research

Volume 2, Issue 2, June 2020, p.23-44 